\title{
O que há e o que falta nos estudos sobre recepção e leitura na web?
}

\author{
L. Graciela Natansohn ${ }^{1}$
}

\begin{abstract}
Resumo: O propósito deste artigo é discutir a vigência teórico-metodológica de algumas categorias amplamente utilizadas na pesquisa de recepção de cunho culturalista, perante a análise do consumo de informação na web. Se pesquisar a recepção nas mídias tradicionais tem sido tarefa complexa, seja pela necessidade de uma abordagem multimetodológica, ou pela instabilidade dos seus resultados, enfrentar a análise do consumo de mídia digital coloca outros desafios ainda pouco ponderados. Os micro processos de interação no mundo digital estão gerando novas categorias de análise, que falam do teor fortemente tecnológico da nova discussão. Texto, leitura e atividade, temas clássicos dos estudos de recepção, precisam de redefinições orientadas para o hipertexto, a navegação e a interação. A tarefa deste artigo se enquadra na tentativa de mapear e revisar estas categorias, em prol de uma teoria sobre a leitura em suporte digital.
\end{abstract}

Palavras-Chave: Recepção - cibercultura - leitura web.

Résume: Le but de cet article se borne à discuter actualité théorique-méthodologique de quelques catégories bien utilisées dans la recherche de réception, par les biais culturaliste, devant l'analyse de la consommation de l'information dans la web. La recherche de réception dans les médias tradictionnels est une tâche complexe, soit par le besoin d'un approche multiméthodologique, soit par l'instabilité de ses résultats. Faire l'analyse de la consommation de média digital met en relief d'outres défis encore peu analysés. Les micro processus d'intéraction dans le monde digital sont en train de gérer de nouvelles catégories d'analyse, qui renforce le poid du technologique dans la discussion. Texte, lecture et activité - thémes classiques des études de réception - ont besoin d'une redéfinition orientée ver le hypertexte, la navigation et l'intéraction. Le tâche de cet article se limite dans la tentative de cataloguer et révisiter ces catégories, vers uns théorie sur la lecture en support digital.

Mots-clé: Réception - cyberculture - lecture web.

\begin{abstract}
The aim of this paper is to discuss about the theoretical and methodological validity of some widely used categories in the research of culturalist reception, in face of the analysis of the consumption of information in web. If to search the reception in the traditional medias has been a complex task, either for the necessity of a multimetodologic boarding, or for the instability of its results, to face the analysis of the consumption of digital media still places other little weighed challenges. The microprocesses of interaction in the digital world is generating new categories of analysis, that speak of the strong technological content of this new discussion. Text, reading and activity, classic subjects of the reception studies, need redefinitions guided for the hipertext, the navigation and the interaction. The task of this article fits in the attempt of mapping and revising these categories, in favor of a theory on the reading in digital support.
\end{abstract}

Key words: Reception - reading web - cibercultura.

\footnotetext{
${ }^{1}$ Jornalista, mestre e doutora em Comunicação e Cultura Contemporânea (UFBA), Professora do Programa de Pós-Graduação em Comunicação e Cultura Contemporânea da UFBA. Pesquisa leitura e recepção midiática com ênfase em jornalismo digital. E-mail: graciela71@gmail.com.
} 
Resumen: El objetivo de este artículo es discutir la vigencia teórico-metodológica de algunas categorias muy utilizadas en investigaciones de recepción de tipo culturalista, frente al análisis del consumo de información en la web. Si pesquisar la recepción en los medios tradicionales ha sido una tarea compleja, ya sea por la necesidad de un abordaje multimetodológico, o por la inestabilidad de sus resultados, enfrentar el análisis del consumo de medios digitales coloca otros desafios aun poco ponderados. Los micro procesos de interacción en el mundo digital están generando nuevas categorías de análisis, que denotan el tenor fuertemente tecnológico de la nueva discusión. Texto, lectura y actividad, temas clásicos de los estudios de recepción, precisan de redefiniciones orientadas para el hipertexto, la navegação y la interacción. La tarea de este artículo se coloca en la tentativa de mapear y revisar estas categorías, en pro de una teoría sobre la lectura en soporte digital.

Palabras-Claves: Recepción - cibercultura - lectura web.

\section{Introdução}

Se alguma vez foi difícil falar de pesquisa em recepção, usos e consumo de meios como um campo teórico mais ou menos coerente ou delimitado, hoje esse panorama complicou-se ainda mais com a emergência das novas tecnologias da informação e da comunicação, que entrelaçam computadores, telefones celulares, PDA e televisão, mediante produtos e formatos diversos. Foi a partir dos anos 90 que algumas pesquisas começaram a se aproximar das tecnologias computacionais para analisar os usos e os efeitos da Internet nos ambientes cotidianos e familiares, como as de Silverstone, Hirsch e Morley (1996), a conformação de sub-culturas juvenis (Miller, 1996), os usos e acessos à tecnologia em função de perfis de gênero e classe (Wheelock, 1996; Cockburn, 1996; Livingston, 1996), o uso dos jogos de computador (games) por parte dos jovens (Haddon, 1996). Todos os estudos, escassos ainda perante a magnitude do fenômeno Internet, manifestam preocupações teóricas e metodológicas face às novas tecnologias e giram ao redor de perguntas genéricas sobre o vasto campo da Internet: o que as pessoas fazem online? Como utilizam os recursos da Internet? Manifesta-se uma preocupação com a tecnologia, com o meio, um descentramento dos textos, das mensagens, dos produtos, para a investigação sobre os usos do meio técnico, de acordo com os perfis dos usuários. Por outra parte, quando o jornalismo instala-se na web através de diversos produtos e formatos (versões digitais de jornais impressos, portais generalistas, buscadores, sites disponibilizadores de conteúdo multimídia, blogs, etc.), os métodos quantitativos de medição de audiência são os mais validados e discutidos, deixando na escuridão a compreensão qualitativa dos processos de recepção, de uso e de 
consumo de produtos no ambiente digital. Isso explica-se, em parte, por que uma compreensão ampla do fenômeno dos usos, das leituras e do consumo de web exige, acreditamos, aproximar tradições de pesquisa bastante diversas.

Justamente, a reflexão que se propõe aqui pretende entrelaçar alguns elementos provenientes das teorias da recepção, especialmente, da tradição das análises textuais de origem culturalista, para aproximá-los aos estudos de cibercultura e jornalismo online, de origem recente dentro do vasto campo de estudos do jornalismo.

\section{Os estudos de audiência de jornalismo web}

Após uma década de existência na rede mundial de computadores, o jornalismo vem se apropriando do ambiente web e passado a se desenvolver aproveitando as especificidades dos recursos digitais. Tanto que hoje praticamente não existem meios impressos sem um complemento em Internet. Mais do que meras transposições do papel para a Internet, o jornalismo web (ou web jornalismo, jornalismo digital ou jornalismo online, todos termos que dizem respeito à utilização de recursos digitais e da web, para produzir e difundir notícias) está transitando uma nova etapa, caracterizada pela autonomia crescente em relação às publicações em papel e criando novos gêneros, recursos produtivos e de distribuição e estratégias informativas, todas específicas dos ambientes digitais. O jornalismo da web tem tomado vôo próprio, marcando uma tendência à independência dos modelos originários do papel e da TV, criando novos formatos e novos produtos que reconfiguram tanto a esfera da produção quanto a recepção.

A audiência também tem seguido o caminho aberto pelo ciberespaço. Pesquisa do Instituto Brasileiro de Geografia e Estatística (IBGE) mostra que o avanço dos microcomputadores superou o crescimento de outros bens duráveis, como máquina de lavar roupa, televisão, rádio, freezer e geladeira. No entanto, a penetração do microcomputador e das redes telemáticas ainda é pequena, comparada com outros bens $^{2}$. Contudo, o crescimento é acelerado e constante.

\footnotetext{
${ }^{2}$ Em 2005, o microcomputador estava presente em 18,6\% das residências de todo o país, sendo que $13,7 \%$ tinham computador com acesso à internet. Já a TV, por exemplo, tem espaço consolidado, com presença em $91,4 \%$ de todos os domicílios. A pesquisa revela também que, em 2005, 21\% do total da população com 10 anos ou mais acessou a internet em algum local (domicílio, local de trabalho, escola, entre outros) nos últimos três meses. In: Folha de S. Paulo.
} 
Dentre as abordagens de pesquisa de audiências na web, as mais desenvolvidas são, sem dúvidas, as que se utilizam de combinação de métodos quantitativos e qualitativos. Alguns estudos baseiam-se na análise dos usuários (user-centric), usandose de questionários sobre amostras para conhecer o perfil sócio-demográfico (idade, sexo, classe social). Em alguns casos controlam-se os usos individuais nos computadores, através de mecanismos que envolvem softwares para registro e descrição dos movimentos do usuário de computador para conhecer os sites mais visitados, os números de páginas visitadas, as ferramentas mais utilizadas, quanto tempo ocupa a leitura, etc. (Rocha, 2003).

Outro conjunto de métodos de pesquisa (que bem poderíamos chamar de métodos de controle) baseia-se nas visitas recebidas aos sites (site-centric). Realiza-se, basicamente, sobre os arquivos de registros dos servidores dos meios, mediante a leitura de logs ou tags, sistema de etiquetas. No $\log$ do servidor fica registrada a entrada de internautas e as páginas que visita, mediante o controle do IP. O problema é que apenas registram computadores (IP), não tendo acesso a informação sobre quantas vezes no dia o mesmo computador visita a página ou pior, algumas redes de computadores dentro de instituições utilizam várias máquinas com o mesmo IP. Os motores de busca também visitam páginas, por tanto, estes mecanismos pouco dizem respeito da verdadeira utilização das pessoas. Em geral, os portais possuem sistemas que apenas medem índice de leitura - por canal ou por matéria - e horário de acesso.

Técnicas de pesquisa aplicadas por Jakob Nielsen preocupam-se com a usabilidade, isto é, a "rapidez com que os usuários podem aprender a usar alguma coisa, a eficiência deles ao usá-la, o quanto lembram daquilo, seu grau de propensão a erros e quanto gostam de utilizá-la” (Nielsen \& Loranger, 2007, xvi). A usabilidade mede a qualidade da interação do usuário com o produto ou sistema, do ponto de vista da facilidade de aprendizado, da eficiência de uso, da capacidade de ser lembrado, enfim, da familiaridade e amigabilidade do produto/sistema com o qual se interage. Combinando técnicas quanti e qualitativas com grupos experimentais, Nielsen trabalha com pesquisa observacional e comportamental, para ver o que os usuários “fazem” com os sites. “A medida mais simples de usabilidade é a taxa de sucesso. As pessoas podem 
usar o site?”, pergunta-se (p. xix). Do ponto de vista metodológico, Nielsen e outros trabalham desenvolvendo técnicas empíricas muito úteis para entender a interação pessoa-computador (interação em sentido muito estrito, no sentido de clicar para obter o que se quer, ou como chama Primo [2007], “interação reativa”, de tipo estímuloresposta). Estes trabalhos observaram também condutas empíricas de leitura nas páginas web, supostamente úteis para indicar aos produtores possibilidades para formatos de texto e edição online. Leitores de movimentos de mouse, leitores de movimento do olhar do usuário, todas técnicas destinadas a conhecer e medir o comportamento individual (o que se lê, por onde se navega, quanto tempo pára-se num local) parecem ser os principais interesses destas pesquisas. Outros têm uma preocupação com o tempo gasto em cada site, página, texto-notícia ou qualquer outro local de navegação, elaborando-se hipóteses (precariamente comprovadas) sobre a capacidade de concentração dos leitores ou sobre a velocidade de leitura de um site em comparação com a página impressa (Prado, 2002).

Um estudo famoso, fora do Brasil, é do Instituto Poynter (www.poynter.org), dos Estados Unidos, cuja pesquisa anual analisa as diferenças e similaridades entre a leitura em papel e online, mediante um software que controla o movimento dos olhos do navegador (com uma espécie de óculos e um sistema de câmeras agregados ao computador) A pesquisa de 2006 publicada em 2007 (http://eyetrack.poynter.org), é interessante e ilustrativa, considerando a quantidade de itens submetidos à observação e análise (quase 300, entre títulos, fotos, chamadas, blogs, podcast, etc.) e a amostra, de 582 pessoas de quatro cidades norte-americanas. Contudo, seus dados não podem ser generalizados para o resto da população e, ainda, não leva em conta mais do que o olhar do usuário (literalmente falando), supondo que olhar é sinônimo de ler.

No Brasil, Ribeiro (2003, 2005, 2006) tem avançado sobre os processos de leitura e letramento digital, e vem realizando interessantes trabalhos baseados na usabilidade para entender até que ponto a diferença na natureza do suporte interfere na qualidade da leitura. Observou a usabilidade dos jornais Folha de S. Paulo e Hoje em Dia, de Minas Gerais, fazendo estudos comparativos entre as versões impressas e eletrônicas. 
O que se deve especializar, no suporte, para que se preserve a qualidade da compreensão? Como o letramento em suporte impresso pode contribuir para a leitura em ambiente eletrônico? A hipótese levantada e sustentada era a de que se o leitor obtém condições mínimas de conforto na lide com o suporte do texto e tem letramento suficiente para a navegação e a leitura naquele suporte, então a qualidade da compreensão e da interpretação dos textos, estejam eles em papel ou em tela, não se modificará de maneira sensível. (...) Quanto à análise das respostas dos leitores aos questionários sobre os textos da Folha de S.Paulo e do Hoje em Dia, ficou demonstrado que todos os leitores/usuários, tendo lido os hipertextos impressos ou eletrônicos, fizeram leituras muito semelhantes, executando inferências demonstrativas e não-demonstrativas demandadas, de maneira muito próxima, sem qualquer prejuízo à compreensão dos textos, ao menos atribuível às dificuldades do suporte (RIBEIRO, 2003, p.77).

Ribeiro desenvolve uma linha de trabalho vinculada às determinantes históricas da leitura e ao letramento digital. Estudos sobre letramento digital versam sobre "o domínio (ou não) pelo leitor dos gestos e as técnicas de ler e escrever em ambientes que empregam tecnologia digital” (Ribeiro, 2006, p.7).

Chegado neste ponto nos perguntamos: o que há e o que falta nos estudos pioneiros analisados até aqui? Acreditamos que há um vazio sobre outros aspectos do processo de leitura e interação gerado na Web, especialmente dos que estão relacionados aos processos de sentido que se deflagram. Parece haver um interesse empírico e instrumental, imediato, em saber o que faz o leitor da web, abrindo-se uma região de sombras sobre os processos de percepção, reconhecimento, interpretação, em relação a processos mais globais, social, político e culturalmente significativos. Ainda, parece que o conteúdo foi deixado de lado porque a preocupação com a representação foi esquecida, substituída pelas novidades que nos colocam as formas da nova comunicação.

\section{Podemos falar de estudos de recepção na Web?}

Recepção é uma palavra extremamente polissêmica que inclui processos conscientes e lógicos de atenção, leitura, inferência, interpretação, compreensão, exposição a mensagens; processos inconscientes da ordem da adesão ou do desejo, e processos valorativos como a aceitação/rejeição, a acordo/discordância, o gosto/desgosto, dentre muitos outros. Todas as combinações entre esses termos são 
possíveis. Herdeira da tradição empirista e tecnicista da comunicação, a palavra carrega em si o peso de uma história da comunicação sem sujeitos.

Quando os estudos culturais acolhem os estudos de recepção, inauguram uma tradição que vê esta não como uma etapa do processo comunicacional, mas como um novo lugar a partir do qual se possa resgatar a criatividade dos sujeitos, a complexidade da vida cotidiana como espaço de produção de sentido e o caráter lúdico e desejoso da relação com os meios, ao dizer de Martin-Barbero (1997). Diversificados e amantes de controvérsias, os estudos culturais abrangem estudos que têm em comum o compromisso de examinar práticas culturais do ponto de vista do seu envolvimento com as relações de poder. Campo transdisciplinar (ou pós-disciplinar, como afirma Jameson), os estudos culturais têm acolhido acirradas polêmicas e debates acerca dos alcances teóricos e políticos dos estudos de recepção. Se em algo há coincidência, é em considerar que a relação entre os meios de comunicação e os públicos não é direta, nem pode ser caracterizada como uma relação causal entre meios, mensagens e receptores, seja qual for a ordem dos fatores. Os melhores aportes realizados aos estudos de recepção foram no sentido de contestar as hipóteses dos efeitos, nas suas variantes funcionalistas e gratificacionistas e, ainda, por seus esforços para pôr em questão as teses da reprodução ideológica (proveniente da visão althusseriana) e discutir muitos dos conceitos trazidos à tona pela reflexão sobre a pós-modernidade.

Nascidos à sombra das mídias de massa, como a rádio e a TV, os estudos de recepção culturalistas sustentaram suas teses em dois aspectos que, face a Internet, devem ser revisados: primeiro, na distância (espaço-temporal e política) irredutível entre as instâncias de produção e de consumo, hoje colocadas em questão pela capacidade de autopublicação, a escrita colaborativa e o jornalismo participativo (em maior ou menor grau) propiciado nas redes telemáticas graças à instantaneidade, à acessibilidade e à velocidade de publicação na rede.

Em segundo lugar, a idéia de público massivo, que diz a respeito de questões teóricas e políticas vinculadas à democracia de massas e às mídias generalistas. Nem a segmentação e fragmentação de públicos propiciada pela televisão por assinatura (pouco estudada no bojo dos estudos culturais) colocou em questão tão brutalmente a idéia clássica de público, como o faz Internet. A relação entre receptores e meio se personaliza: fala-se de “interação pessoa-computador” e já não de meios-públicos. 
Usuário é a nomenclatura mais freqüentemente utilizada, mas também, navegante, visitante, leitor (Black, 1997), interator (Murray, 2003), leitor imersivo (Santaella, 2004), cibernauta (Correia, 2006), leito-autor (Moreno, 2002) públicos usuários (Boczkowski, 2006), dentre outros. Apenas quando se medem acessos em forma quantitativa, usam-se as palavras audiência ou visitantes. Interessante é perceber que o estudo dos micro-processos de uso estão substituindo as macro-categorias típicas (usadas, mais do que nada, nos estudos de recepção interessados nas relações entre uso, consumo e recepção de mídia) tais como a classe, a raça, o gênero. Será que os substantivos coletivos já não são tão pertinentes na hora de caracterizar o receptor de mídia digital? Os debates, no seio dos estudos culturais, versavam sobre quais determinações eram mais pertinentes a respeito da influência da mídia sobre esse agregado chamado público: se a classe, se a raça, se o gênero. Essas categorias perderam sua espessura teórica e política? Que podem nos trazer para entender a recepção de mídias web?

Para pesquisadores como Scolari (2004), um dos poucos que trabalha na tentativa de integrar ciência cognitiva e semiótica na análise de produtos Web, os grandes relatos otimistas sobre os macroprocessos na rede digital, típicos dos 90, careciam de consistência teórica, motivo pelo qual ele propõe encarar a análise das micro-interações, dos micro-eventos perante a tela, para entender, sim, a lógica dos sistemas gerais que regem a ecologia das interfaces. Desta forma, recupera-se a relação entre o micro e o macro, isto é, entre os eventos estruturantes e as estruturas estruturadas.

\section{Ler, ver, olhar, tocar...}

Entre os indivíduos e as maquinas digitais acontecem processos que envolvem não apenas a visão e a percepção, mas “inferência, julgamento, memória, reconhecimento, conhecimento, experiência, prática” (Santaella, 2004, p.23). Ler não é um processo automático, é um trabalho, um processo de construção “desconcertante, labiríntico, comum e, contudo, pessoal” (Manguel, apud Santaella, 2004, p. 23). Não se trata de um fenômeno individual e pessoal, mas de um processo "generativo que reflete a tentativa disciplinada do leitor de construir um ou mais sentidos dentro das regras da linguagem”. (Santaella, op.cit.p.23) 
O mito da dificuldade de leitura na tela está, aos poucos, caindo por água abaixo. Estudos internacionais mostram que não é a tela a que impede a leitura na Web. Pesquisa com alunos no País Basco testaram a rapidez da leitura na tela e no papel e a capacidade de retenção em um e outro suporte, com alunos de jornalismo. Os resultados demonstraram que os leitores de telas foram mais rápidos que os de papel e demonstraram um melhor nível de compreensão do que foi lido (Armentia et alii, s/d)

\footnotetext{
Aunque diversos estudios -Nielsen, García, Rich...- insisten en la desventaja de la lectura sobre soporte electrónico, con respecto a la realizada sobre el tradicional diario en papel; resulta, cuando menos, dudoso que dichas limitaciones sean tales para los jóvenes lectores de la generación del "Game boy"; es decir, para aquellos potenciales consumidores de información, acostumbrados a la presencia de un ordenador en sus hogares y para quienes la lectura en una pantalla resulta tan familiar como el realizarla sobre el papel (Armentia et alii, op.cit)
}

Por outra parte, o termo leitura tem uma história que a vincula à ilustração e aos estudos literários (os estudos de recepção de mídia também utilizam esse termo) apesar de que nem sempre seja ler o que se faz com eles: ver, ouvir, apenas sentir, olhar, tocar. Se bem na atualidade se vem usando cada vez mais o conceito amplo de leitura, como um jogo de associações entre imagens, sons e letras, sobrevive a noção que a associa ao texto impresso, á concatenação de palavras. A suposta supremacia do livro sobre o computador exemplifica bem a permanência desses conceitos: supõe-se que os jovens "não lêem” pois navegam na Internet o tempo todo.

\section{Atividade e interatividade}

Pesquisadores como David Morley e John Corner há dez anos que vêm afirmando que o tema do poder mediático como questão política tem começado a desaparecer da agenda de investigação em comunicação. E relacionam esta suposta despolitização com algo que está no bojo dos debates nos estudos de recepção: a questão da atividade e da autonomia da audiência e o poder de decisão das pessoas. Melhor dizendo, a relação entre a atividade da audiência e o poder de "contestação" ou "resistência” aos discursos dominantes, a relação entre o sentido dos textos midiáticos e o poder. Ironicamente, com bastante freqüência nos deparamos com análises sobre novas mídias e Internet nas quais parece haver-se descoberto a atividade apenas nos usuários dos computadores, sob 
o nome de interatividade. Na verdade, a suposta passividade dos leitores - usuários receptores das mídias tradicionais morreu apenas apareceram os trabalhos sobre usos e gratificações, que introduziram o conceito de audiência ativa (Morley, 1996) ${ }^{1}$. O que trazem, justamente, os estudos de recepção, é o suposto de que toda recepção é uma atividade produtiva.

Para os estudos culturais, as relações de poder na sociedade e a economia política dos meios de massa influenciam os conteúdos da comunicação e, indiretamente, as respostas da audiência. "Indiretamente” significa sair das visões mecanicistas causaefeito e introduzir a complexidade da relação entre sujeitos, textos e mídias. Interessante é lembrar, a esta a altura, o que David Morley advertia sobre a proliferação de leituras contestatórias e resistentes que os pesquisadores (de televisão) achavam por todas partes, graças à percepção (à descoberta, poderíamos dizer) da interatividade entre os sujeitos e as mídias. Do ponto de vista político, este otimismo epistemológico colocava na interação uma vontade de poder que inclinava a balança do lado dos públicos, de tal maneira que estes teriam a última palavra e seriam soberanos para decodificar mensagens a seu bel-prazer. Esta espécie de inversão do paradigma tradicional dos efeitos, que destaca a recepção como “o” lugar do poder (do público) em vez da emissão, foi chamada por Morley, com ironia, como "democracia semiótica do pluralismo moderno” (Morley, 1996, p. 49) que simplifica, novamente, a questão do poder dos meios, eleva a audiência a categoria de soberana, colocando o mercado (e o Ibope) como único guia para os conteúdos dos meios, justificando e legitimando as políticas neoliberais, isto é, a desregulação das redes comunicacionais num mercado altamente desigual ${ }^{2}$.

Isto vem à tona porque quando nos adentramos no campo das pesquisas em cibercultura e jornalismo digital, todavia há vozes que colocam na interatividade telemática atributos intrinsecamente superiores, do ponto de vista social e político e funcionam como discursos utópicos, onde a técnica seria capaz de solucionar os grandes problemas da comunicação. Neste sentido, duas observações: quando se fala de audiências de jornalismo é preciso não cair na armadilha de pensar na demanda do público como algo apriori, pré-existente e desvinculado da oferta. A resposta freqüente à questão sobre o que querem as audiências, normalmente é formulada em termos de quais as reações dos usuários à oferta de conteúdos e serviços. As formas de 
propriedade dominante do jornalismo (comercial e vinculado a grandes empresas) justificam tais formas de tratar da audiência e o consumo, já que trata-se de um produto cujo objetivo é ser consumido pela maior quantidade de pessoas. O que não justifica que, na academia e no campo teórico, se assimile acriticamente tal modelo.

A segunda é que - não está demais lembrar - não foi fácil pesquisar as questões tecnológicas dentro do campo das teorias críticas e culturalistas. O debate sobre a tecnologia sofreu, até entrados os 90, de acusações fortemente ideologizadas, que denunciavam os efeitos homogeneizadores da tecnologia eletrônica. "O resto era ideologia, pensamento integrado, macluhanismo electro-imperialista disfarçado de teoria social” (Scolari, 24, p. 17). Essa situação dificultou a aproximação entre a duas tradições. Só nos anos 90, como dizemos antes, esta situação começaria a mudar.

Dez anos após o surgimento do jornalismo online, ainda aparecem prognósticos sobre a democratização do circuito da informação em base à interatividade. Mas também aparecem diagnósticos um pouco mais realistas.

Há dez anos o jornalismo digital trouxe uma esperança em tornar os meios e comunicação mais democráticos com a proliferação dos diários na web, pois era prometida uma interação plena do internauta que o transformaria em produtor da notícia. Hoje, a troca da comunicação e a inversão de papéis entre consumidores e produtores da notícia raramente ocorre nos jornais digitais ao contrário do que professavam teóricos do ciberespaço (QUADROS, 2005).

A “liberação do pólo emissor” prometida pelos pesquisadores em cibercultura, em se tratando de jornalismo na web, está bastante longe, como mostram alguns trabalhos $^{3}$. Característica inerente à comunicação humana - toda linguagem é intrinsecamente interação, diálogo - na interatividade digital há uma complexidade maior para sua análise, dado que o receptor é solicitado pelo texto a construir, individualmente, seu próprio percurso de leitura, a partir de uma unidade textual ofertada. A seqüência de leitura é criada individualmente e objetivada materialmente (na medida em que a tecnologia pode registrar o percurso de leitura através dos links ou mediante outro tipo de software, como já descrevemos acima). Além de uma atividade mental estimulada por uma série de textos, o percurso de leitura (pelo menos no que se refere à percepção audiovisual) se constitui em uma produção que pode ser empiricamente observada, medida, analisada. Todavia, a possibilidade de personalizar 
os conteúdos individualiza mais ainda o percurso de leitura, diferenciando mais a oferta a nível individual (num ambiente, várias ofertas) e dificultando a generalização nas análises. Além disso, o sujeito pode dispor de certos recursos interativos que possibilitam que o usuário seja simultaneamente emissor e receptor.

Se para os estudos culturais a recepção é uma produção (de sentido), na web essa produção vai além da pura atividade interna: adquire uma materialidade diferencial, seja porque há um registro material da leitura ou porque além de receptor, o sujeito pode alimentar o circuito comunicacional através de um fazer concreto (enviar mensagens, propor pautas, comentar notícias, ser fonte de notícias, etc.).

Qual pode ser o interesse dos estudos culturais de recepção, perante uma tecnologia como a Internet como suporte para a informação? Como dizemos, muitos autores têm criticado os estudos de consumo de novas tecnologias pelo viés da despolitização que atende cada vez mais os micro processos das relações entre o sujeito e a tela (a leitura, em sentido restrito), abandonando as preocupações pelas relações com as macroestruturas dos sistemas mediáticos e da sociedade. Essa preocupação acende o debate antigo entre o macro e o micro. O que a pesquisa em novas mídias pode reconstituir, justamente, é a articulação entre os micro-processos de interação (o "fazer clic”, como diz Scolari) para a evolução das gramáticas de interação, em contextos de uso. Unir, na análise, os microprocessos de leitura e macro estruturas (de classe, de gênero, de poder, econômicas) a partir das quais o campo do jornalismo se desenvolve, onde a interação se realiza e onde as potencialidades transformadoras da teoria podem ser plasmadas.

As análise de recepção de jornalismo na web devem centrar a atenção na arquitetura e no funcionamento das interfaces jornalísticas, nas estruturas discursivas que as sustentam e as estratégias que daí se desdobram, as imagens de locutores e interlocutores, isto é as instruções de leitura que os pontuam para, após a elaboração de hipótese sobre seu consumo, desenvolver estratégias de apreensão do processo de navegação com suas complexidades. Em suma, através da análise textual pode se priorizar a reconstrução, em termos qualitativos, da estrutura e dos processos de geração de sentido.

Se todo texto contém um projeto de relação comunicativa, isto é, elabora seu “outro”, institui seu interlocutor, prevê uma interação com um leitor - pela 
dialogicidade constitutiva de todo texto - nos ambientes digitais este simulacro de diálogo se materializa de uma forma inédita, pois o leitor “entra”, via mouse, na tela. Como descreve Scolari (2005, p. 57) o simulacro do corpo do usuário aparece na tela sob a forma do cursor. Todavia, na medida em que o texto da tela é incompleto (pois depende do percurso de leitura criado pelo usuário) a figura do sujeito enunciador perde seus limites, se torna difuso. O usuário deixa suas marcas no texto, colabora, de alguma forma, com o texto virtual.

\section{Concluindo...}

O que nos interessa é destacar que, para os estudos de recepção (ou leitura, como preferimos chamá-los) de jornalismo na web, todavia, a instancia da produção discursiva também continua a ser importante na análise do consumo de mídias web, na medida em que qualquer interação, seja a mais desviante ou a mais passiva, se realiza a partir de uma oferta discursiva. A análise da instancia de produção na web se complica tanto pela dinamicidade quanto pela liquidez dos processos de interação. A interface gráfica substitui a mise en scène do arranjo televisual, por exemplo, e como ela, não é um espaço neutro. Longe de ser uma atividade automática, natural e transparente, a interação com as máquinas, com os outros e com os produtos se dá através das interfaces. Considerando que o design de uma interface é um conjunto de processos, regras e convenções que permitem a comunicação entre sujeitos e máquinas e sujeitosmaquinas-sujeitos, enquanto rede cognitiva de interações é o que permite determinada arquitetura da informação com seus respectivos desdobramentos e complexidades narrativas e interativas. A interface é uma "gramática da interação” entre humanos e computadores (Scolari, Op.Cit., p.42) e é um produto de um sujeito desenhista. No caso de mídia web relação será determinada: a) pelo tipo de interface gráfica, b) pelo sistema operacional, c) pelo sistema de publicação definido pela instituição jornalística, d) pela arquitetura da informação, seu desenho e as opções de navegação e interação prédefinidas (produção de pautas, fóruns, chats, comentários, blogs, recursos multimídia, de memória, de personalização). Todavia, a relação do usuário com a interface vai depender do tipo de conexão com a rede, do dispositivo através do qual acessa um determinado site (computador doméstico ou portátil, celular, agenda eletrônica, etc.), todo isso atuando no processo de interação. Todo isso é o que vai determinar a 
gramática da interação, isto é, os dispositivos e as regras que regulam a interação possível. Esta naturalização característica da interface é o que retifica a interação sujeito-máquina; a interação, na verdade, não depende do usuário nem da máquina, mas vai estar fortemente influenciada pelo desenhista, quem concebe e projeta o sistema. Em termos semióticos, a relação não se estabelece entre um sujeito e um sistema senão entre dois simulacros, entre a estratégia do leitor e a estratégia do desenhista (Scolari, Op. Cit. p. 79). Esta perspectiva desfaz qualquer ilusão de total liberdade de escolha do receptor. No máximo, as escolhas se ampliam consideravelmente em comparação com as mídias tradicionais.

Estas questões são apenas algumas das que devem ser mapeadas para pensar a relação entre os receptores e o jornalismo digital. Perante este panorama, em que medida as características deste novo medium afetam os pressupostos das teorias da recepção? Com as mídias digitais aconteceu o contrário que com a televisão: fascínio e entusiasmo de muitos perante um novo mundo, onde, segundo seus porta-vozes mais otimistas, os últimos (receptores) serão os primeiros (emissores). Supostos tais como que a comunicação baseada na demanda seria superior à comunicação baseada na oferta ou que as novas tecnologias resolvem os problemas da democracia, são produto de certo determinismo tecnológico reinante nas análises mais superficiais. Em palavras de Wolton (2003, p. 31-32), "somente a ausência de uma cultura teórica permite a idéia de uma mudança radical de sociedade ao ritmo das novas tecnologias”.

Uma teoria dos usos e leitura na web que seja auto-reflexiva, que leve em conta a espessura teórica das relações entre sujeitos e mídias digitais, que re-coloque novamente a questão do sujeito e da subjetividade no consumo de informações na web e que repense o papel do jornalismo na sociedade, está ainda para ser feita e os primeiros passos, exploratórios, estão dados. É preciso ir além porque acreditamos, junto a Wolton, que pensar o consumo de mídias significa bem mais do que catalogar condutas perante um computador é pensar numa teoria do vínculo social.

\section{Referências bibliográficas:}

ARMENTIA, Jose I., CAMINOS, José M., ELEXGARAY,J. e MERCHÁN,I.. La información en la prensa digital: redacción, diseño y hábitos de lectura. In: http://www.ehu.es/zer/zer8/8armentia9.html (capturado em 22/09/2007). 
BLACK, Roger. Websites que Funcionam. São Paulo: Quark, 1997.

BOCZKOWSKI, Pablo. Digitalizar las noticias. Innovación em los diários online. Buenos Aires: Manantial, 2006.

COCKBURN, C. El circuito de la tecnologia. Gênero, identidad y poder. In: Los efectos de la nueva comunicación. SILVERSTONE, R.; HIRSCH, E. (Eds.). Barcelona, Bosch, 1996, p.5980.

CORREIA, Denize. Estudos sobre Comunicação e Cibercultura no Brasil: Conceitos, Tendências e Clusters. Razón Y Palabra. México, octubre-noviembre 2006. Disponível em: http://www.cem.itesm.mx/dacs/publicaciones/logos/actual/dcorrea.html . Capturado em 22/10/2006.

CURRAN, J.; MORLEY, D.; WALKERDINE, V. Estudios Culturales y Comunicación: Análisis, producción y consumo cultural de las políticas de identidad y el posmodernismo. Buenos Aires: Paidós, 1998.

HADDON, Leslie. Explicaciones sobre el consumo de tecnologias de la comunicación y la información. El ejemplo del ordenador doméstico. In: Los efectos de la nueva comunicación. SILVERSTONE, R.; HIRSCH, E. (Eds.). Barcelona, Bosch, 1996, p.127-146.

LIVINGSTON, Sonia. El significado de las tecnologías domésticas. Un análisis del constructo personal de las relaciones familiares respecto del gênero. In: Los efectos de la nueva comunicación. SILVERSTONE, R.; HIRSCH, E. (Eds.). Barcelona, Bosch, 1996, p.169-192.

MARTIN-BARBERO, Jesús. De los Medios a las Mediaciones: Comunicación, Cultura y Hegemonía. Barcelona: Gustavo Gili, 1987.

MILLER, D. The Young and the Restless (Los jóvenes y los inquietos) en Trinidad. Un ejemplo de lo local y lo global en el consumo de masas. In: Los efectos de la nueva comunicación. SILVERSTONE, R.; HIRSCH, E. (Eds.). Barcelona, Bosch, 1996, p.237-262.

MORENO, Isidro. Musas y nuevas tecnologias. Barcelona: Paidos, 2002.

MORLEY, David. Televisión, audiencias y estudios culturales. Buenos Aires: Amorrortu, 1996.

MURRAY, J.H. Hamlet no Holodesk. O futuro da narrativa no ciberespaço. São Paulo: Ed Unesp, 2003.

NIELSEN, jakob. LORANGER, Hoa. Usabilidade na Web. Projetando sites com qualidade. Rio de Janeiro, Elsevier, 2007.

PRADO, Ana. Uma notícia a cada 90 segundos: estudo de caso de um jornal on-line. In: Pauta geral, Revista de Jornalismo. Salvador, Calandra, 2002.

PRIMO, Alex. Interação mediada por computador. Comunicação, cibercultura, cognição. Porto Alegre, Sulina, 2007. 
QUADROS, Claudia. Público, como vai? In: III Encontro Nacional de Pesquisadores em Jornalismo. Florianópolis, S.C: Sociedade Brasileira de Pesquisadores em Jornalismo, 2005.

RIBEIRO, Ana Elisa. Leituras Sobre Hipertexto: trilhas para o pesquisador. Trabalho apresentado no GT Hipertexto: que texto é esse?, no XI Simpósio Nacional de Letras e Lingüística e I Simpósio Internacional de Letras e Lingüística, Uberlândia, nov. 2006.

RIBEIRO, Ana Elisa. Ler na tela. Novos suportes para velhas tecnologias. Dissertação de mestrado. PPG em Estudos Lingüísticos. UFMG. Belo Horizonte, 2003.

RIBEIRO, Ana Elisa. Os hipertextos que Cristo leu. In: ARAÚJO, Júlio César e BIASIRODRIGUES, Bernardete. Interação na Internet. Novas formas de usar a linguagem. Rio de Janeiro: Lucerna, 2005. p. 124-130.

ROCHA, José Antonio Meira da. Espaço e Tempo no Jornalismo Online. Dissertação de Mestrado defendida no Programa de Pós-Graduação em Comunicação da Universidade do Vale do Rio dos Sinos - Unisinos. São Leopoldo (RS), agosto de 2003.

SANTAELLA, Lúcia. Navegar no ciberespaço. O perfil cognitivo do leitor imersivo. São Paulo: Paulus, 2004.

SCOLARI, Carlos. Hacer Clic. Hacia uma sociosemiótica de las interacciones digitales. Barcelona; Gedisa, 2004.

SILVERSTONE, R.; HIRSCH, E.; MORLEY, D. Tecnologías de la información y de la comunicación y la economía moral de la familia. In: Los efectos de la nueva comunicación. SILVERSTONE, R. ; HIRSCH, E. (Eds.). Barcelona, Bosch, 1996, p.39-58.

WHEELOCK, Jane. Ordenadores personales, gênero y um modelo institucional para el âmbito doméstico. In: In: Los efectos de la nueva comunicación. SILVERSTONE, R.; HIRSCH, E. (Eds.). Barcelona, Bosch, 1996, p 147-168.

WOLTON, Dominique. Internet, e depois? Uma teoria crítica das novas mídias. Porto Alegre: Sulina, 2003. 